\title{
Health Science

\section{Challenges and perspectives of health informatics and its management in developing Asian countries}

\author{
Shaima S. Ali Miraj, PhD \\ Department of Public Health Management, College of Health \\ Sciences, Saudi Electronic University Riyadh, Saudi Arabia
}

\begin{abstract}
The health care industry has generated large amounts of complex and diverse data, driven by record keeping, compliance and regulatory requirements and patient care, however in absence of proper management and judicious use of health informatics and data generated through it, the vital information is not being used for the benefit of patients. Studieshave shown that costs can be dramatically reduced in health care by using health informatics and data collected over long periods of time, like patient's history, recurrence of pathologies, genetic trends, in heritance, and many other statistical tools, which can be used for huge benefits of patients. But all these require huge funds, proper training, judicious and honest use of such collected information, brilliant research - updated physicians, experts and managers can make wonders in health care delivery, benefitting both the government and the patients by synergistic use of health information system generated data. The literature indicates that these systems and their implementation is limited and at times spasmodic in developing as well as low-income countries, largely because of the financial and implementation challenges these countries face. These challenges are likely due to technological, organizational, financial or human resources barriers. With no signs of improvement, despite several governments claiming to soothe balms on the self-inflicted injuries, the health insurance sector, NGOs, WHO,IMF, World Bank and other benevolent rich nations will have to come together to fulfil the future vision of Health For All especially in poor and developing countries. To tackle the problems of corruption, malpractices in health care where health informatics data in such situations can be exploited for fraud and malpractices, better role of governments, sincere controlling and regulatory authorities in association with International Agencies is recommended to streamline these issues. Data analytics and applications in healthcare are at a nascent stage of development, but rapid advances in platforms and tools with proper management and control can accelerate their maturing process in developing nations as well.
\end{abstract}

KEY WORDS: DATA INFORMATICS, MANAGEMENT, SYNERGISTIC USE FOR PATIENT CARE

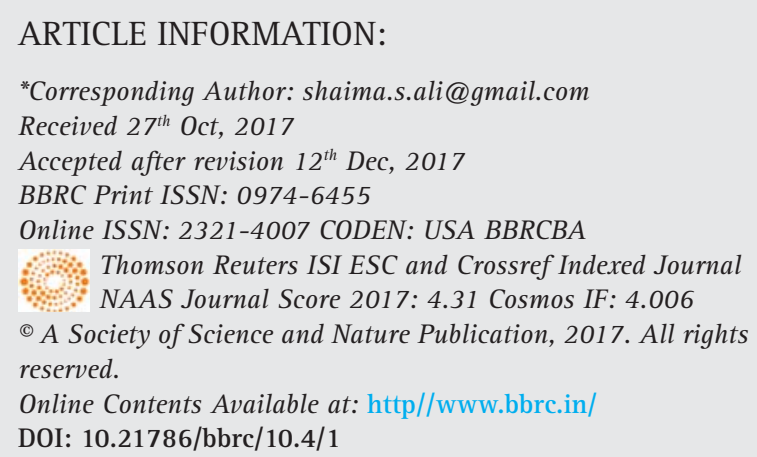




\section{INTRODUCTION}

Healthcare industry has always been in a complex situation of handling or rather mishandling huge data of patients or in using health informatics, over a long period of time, as data collected but not judiciously used is as good as data wasted. The health careindustry has generated large amounts of complex and diverse data, driven by record keeping, compliance and regulatory requirements, and patient care, the latter seldom in priority. Looking to the recent computerisation of health care centres worldwide including the poor and developing nations, the current trend is toward rapid digitization of these large amounts of data.New data analytic tools to facilitate scalable, accessible and sustainable data infrastructure for effective management of large, multiscale, multimodal, distributed and heterogeneous data sets and convert data into knowledge for support cost-effective decision aids, disease management, and care delivery need to be developed, especially in health care centres of developing nations.

Driven by necessity, and the potential to improve the quality of healthcare delivery along with reducing the costs, these massive quantities of data (known as 'big data') hold the promise of supporting a wide range of medical and healthcare functions, including among other clinical decision support, disease surveillance, and population health management.They also include initiatives that enable use of data analytics in health systems for improved clinical decision making, enhanced efficiency of care provision, policy development and policy implementation, (Burghard 2012, Dembosky 2012, Feldman et al., 2012 Fernande et al., 2012 and Raghupati \&t Raghupati 2014 Andreau Perez et al 2015 and Sweeney 2017).

Reports demonstrate that data from the U.S. healthcare system alone reached, in 2011, 150 exabytes that's enough data to fill a stack of DVDs that would reach from Earth to Mars (NCBI, 2017). Remarkably, that volume continues to double every two years. At this rate of growth, data for U.S. healthcare will soon reach the zettabyte ( $10^{21}$ gigabytes) scale and, not long after, the yottabyte (10 ${ }^{24}$ gigabytes), (IHTT (2013). By definition, big data in healthcare refers to electronic health data sets so large and complex that they are difficult (or impossible) to manage with traditional software and/or hardware; nor can they be easily managed with traditional or common data management tools and methods. Big data in healthcare is overwhelming not only because of its volume but also because of the diversity of data types and the speed at which it must be managed, (Frost and Sullivan 2016).

Developed nations which have huge amount to spend on health care both government and insurance based, can think of proper use of such technologies, infrastructure and latest developments in synergistic use of big data. Various studies in these countries have shown that costs can be dramatically reduced in health care by using health informatics and data collected over long periods of time, like patient's history, recurrence of pathologies, genetic trends, in heritance, and many other statistical tools, which can be used for huge benefits of patients. But all these require proper training, judicious and honest use of such collected information, brilliant research - updated physicians, experts and managers can make wonders in health care delivery, benefitting both the government and the patients by synergistic use of health information system generated data.

In one very famous example, California-based Kaiser Permanente associated clinical data with cost data to generate a key data set, the analytics of which led to the discovery of adverse drug effects and subsequent withdrawal of Vioxx from the market. Researchers at the Johns Hopkins School of Medicine discovered they could use data from Google Flu Trends to predict sudden increases in flu-related emergency room visits at least a week before warnings from the Centre for Disease Control. Likewise, the analysis of Twitter updates was as accurate as (and two weeks ahead of) official reports at tracking the spread of cholera in Haiti after the January 2010 earthquake, (IHTT 2013).

These electronic based health record systems like, Electronic Medical Record (EMR) Health Information System (HIS ) are considered essential components of any healthcare organization, (Mitchell and Yaylacicegi 2013). Healthcare providers such as physicians and nurses spend long periods of time during their workday collecting information from patients, (Conrick, 2006). On the other hand, developing countries have tended to lag behind in the adoption and implementation of HIS and EMR systems, or even a basic health data system, (Sinha et al., 2013). The literature indicates that these system and their implementation is limited and at times spasmodic indeveloping as well as low-income countries, largely because of the financial and implementation challenges these countries face. These challenges are likely due to technological, organizational, financial or human resources barriers, (Luna et al., 2014, Naseem et al., 2014).

In developed countries like Saudi Arabia, initiatives for implementing Health Information System and other EMR systems have been occurring over the last four decades, (Altuwaijri 2008 and Hasanian et al., 2014). Over these past decades Saudi Arabia has spent billions of dollars to develop and improve the quality of health care. As well as funds to assist EMR implementation, the Saudi Ministry of Health (MOH) has made clear its intention to implement HIS nation-wide, (Altuwaijri 2008). Previous research showed that HIS implementation was low within Saudi public hospitals in its early stages, but Saudi Arabia is a developing country, it has made remarkable progress and achievements in health 
care and its management, (Aldosari 2014, Alkhamis 2012, 2017). There are a number of major hospitals and healthcare organizations that have attained distinguished achievement in use of health informatics and other high technology gadget implementation in Saudi Arabia and many more well equipped public hospitals and centres have been developed, (Hasnain et al., 2014, 2015 and Alkahmis 2012, 2017).

Unfortunately, situation in poor and developing Asian countries like Bangla Desh, Afghanistan, Pakistan, Sri Lanka and India is in stark contrast and is seriouslyalarming with reference to the use of health care informatics and data of patients collected for improving and reducing cost of healthcare. Leaving aside most of the state of the art private and few government hospitals in metro cities like Delhi, Mumbai, Bangalore, Chennai, Kolkata which are beyond access to general population, majority of hospitals serving thge public are in sorry state of affairs with regard to use of HIS, EMR and other state of the art technology based health informatics tools. Where it is extremely difficult to run heath care centres owing to severe shortage of funds, manpower, infrastructure, medicines and other bare necessities, how we can collect, generate and maintain health care data and keep it alive for better future use?

Health care data in such situations can be exploited for personal gains, or it can go waste for want of mismanagement, corruption, legal battles, fraud and malpractices in several sectors like the insurance, corporate health policy claims, government reimbursements and many others. Health, being one of the most essential and basic needs of an individual makes it a lucrative soft target for corruption worldwide especially in developing countries where poor or no control exists on health administration and management. Health having unique dimensions is susceptible to both economic and political influences and its corruption not only involves monetary incentives, but also involves corruption of knowledge, experience and other practices, thus use of advance technologies like health informatics, data collection and its maintenance in this sector warrant lot of sincerity, dedication, sacrifice and character, both from the government agencies and other parties.In this present scenario, where $50 \%$ of world's population cannot afford essential health services, where each year about 100 million people including in India, are being pushed into poverty because they have to pay for health care out of their own pockets, (0OPs) we can only expect a miracle for better health for all in future by use of health informatics.

Tracking Universal Health Coverage: (2017) Global Monitoring recent Report by the World Bank and the WHO-TUHC (2017), it has been revealed that currently 800 million people spend at least $10 \%$ of their earnings on health expenses for themselves, a sick child or other family member. For almost 100 million, these expenses are high enough to push them into extreme poverty, forcing them to survive on a meagre 1.90 US dollars or less a day. The report looks at catastrophic spending on health on the basis of out of pocket expenditures exceeding $10 \%$ and $25 \%$ of house hold total income or consumption. About one sixth of households in India (exceeding $10 \%$ household income) and $3.9 \%$ (exceeding 25\% household income) bear such spending exceeding a household's ability to pay without reimbursement by a third party, WHO UHC (2017).

\section{FUTURE PERSPECTIVES}

With no signs of improvement, despite several governments claiming to soothe balms on the self-inflicted injuries, the health insurance sector, the Third Party Assurances, (TPAs), NGOs, WHO,IMF, World Bank and other benevolent rich nations along with the OOPs will have to come together to fulfil the future vision of Health For All especially in poor and developing countries. To tackle the problems of corruption, malpractices in health care where health care data in such situations can be exploited for fraud and malpractices, the role of sincere controlling and regulatory authorities in association with International Agencies can be recommended. Health, being one of the most essential and basic needs of an individual makes it a lucrative soft target for corruption worldwide especially in developing countries where poor or no control exists on health administration and management. Health having unique dimensions is susceptible to both economic and political influences and its corruption not only involves monetary incentives, but also involves corruption of knowledge, experience and other practices, thus use of advance technologies like health informatics, data collection and its maintenance in this sector warrant lot of sincerity, dedication, sacrifice and character, both from the government agencies and other parties.

However in the years to come we cannot keep our eyes closed and get into the ground to hide, let us start doing the innovations with a zeal enthusiasm and dedication amidst the challenges which are many and look like mountains. At minimum, health information analytics platform in healthcare we must support the key functions necessary for processing the health related data of patients. The criteria for platform evaluation may include availability, continuity, ease of use, scalability, ability to manipulate at different levels of granularity, privacy and security enablement, and quality assurance. In addition, while most platforms currently available are open source, the typical advantages and limitations of open source platforms apply.

To succeed, big data analytics in healthcare needs to be packaged, so it is menu-driven, user-friendly and transparent. Real-time big data analytics is a key requirement in healthcare. The lag between data collection and processing 
has to be addressed. The dynamic availability of numerous analytics algorithms, models and methods in a pull-down type of menu is also necessary for large-scale adoption. The important managerial issues of ownership, governance and standards have to be considered. And woven through these issues are those of continuous data acquisition and data cleansing. Health care data is rarely standardized, often fragmented, or generated in legacy IT systems with incompatible formats. This great challenge needs to be addressed as well, (Raghupath and Raghupath 2014).

Health informatics pertaining to huge data analytics has the potential to transform the way healthcare providers use sophisticated technologies to gain insight from their clinical and other data repositories and make informed decisions. In the future we'll see the rapid, widespread implementation and use of big data analytics across the healthcare organization and the healthcare industry. To that end, the several challenges highlighted above, must be addressed. As big data analytics becomes more mainstream, issues such as guaranteeing privacy, safeguarding security, establishing standards and governance, and continually improving the tools and technologies will garner attention. Governments as participants and NGOs as watch dogs along with funding of helping hands like the IMF, WHO, UN and other philanthropic foundations like Bill Gates and others can make it possible with firm determination and will power to do it.

Big data analytics and applications in healthcare are at a nascent stage of development in Asian nations, but rapid advances in platforms and tools can accelerate their maturing process. Modern health sector has a questionable history, driven by hunger of profit through the inhibition and discouragement of less profitable therapies and treatments. There are many areas inhealth care system which on given occasions allow dubious practices including corruption to pierce in. It's important we have a check on these malpractices, which can disturb all the good work being carried out in this noble profession of serving humanity.

\section{REFERENCES}

Aldosari B. (2014) Rates, levels, and determinants of electronic health record system adoption: A study of hospitals in Riyadh, Saudi Arabia. International Journal of Medical Informatics .

Alkhamis A. (2012) Health care system in Saudi Arabia: an overview. East Mediterr Health J 2012;18:1078-9.

Alkhamis A. (2017) Critical analysis and review of the literature on healthcare privatization and its association with access to medical care in Saudi Arabia J of Infection and Public Health Vol 10 Issue 3 258-268

Altuwaijri M. (2008) Electronic-health in Saudi Arabia. Just around the corner? Saudi Med J 29:171-8.

Burghard C. (2012) Big Data and Analytics Key to Accountable Care Success. 2012.
Conrick M. 2006 Health Informatics: Social Science Press, Melbourne

Dembosky A. (2012) Data Prescription for Better Healthcare, Financial Times, December 12, 2012, p. 19.2012.

Feldman B, Martin EM, Skotnes T. (2012) Big Data in Healthcare Hype and Hope." October 2012. Dr. Bonnie 360. 2012.

Fernandes L, O'Connor M, Weaver V. J Ahima (2012) Big data, bigger outcomes; pp. 38-42.PubMed

Frost \& Sullivan (2017) Drowning in Big Data? Reducing Information Technology Complexities and Costs for Healthcare Organizations. http://www.emc.com/collateral/analyst-reports/frostsullivan-reducing-information-technology-complexities-ar.pdf

Hasanain R, Vallmuur K, Clark M. (2014) Progress and Challenges in the Implementation of Electronic Medical Records in Saudi Arabia: A Systematic Review. Health Informatics - An International Journal 2014; 3.

Hasnain R A., K Vallmuur and M Clark (2015) Electronic Medical Record Systems in Saudi Arabia : Knowledge and preferences of health care professionals J.of Health Informatics in Developing Countries Vol 9 No 1 23-31

Javier Andreu-Perez ; Carmen C. Y. Poon ; Robert D. Merrifield ; Stephen T. C. Wong ; Guang-Zhong Yang( 015) Big data For Health IEEE Journal of Biomedical and Health Informatics (Volume: 19, Issue: 4, July 2015 )

Luna D, Almerares A, Mayan JC(2014) Health Informatics in Developing Countries: Going beyond Pilot Practices to Sustainable Implementations: A Review of the Current Challenges. Healthc Inform Res 20:3-10.

Mitchell S, Yaylacicegi U. (2013) Analysis of Electronic Health Record Implementation and Usage in Texas Acute Care Hospitals. Journal of Information Systems Applied Research 2013;6:4 9-56.

Naseem A, Rashid A, Kureshi NI. (2014) E-health: effect on health system efficiency of Pakistan. Ann Saudi Med 34:59-64.

NCBI (2017) Big data analytics in healthcare: promise and potential. Available at: http://www.ncbi.nlm.nih.gov/pmc/articles/PMC4341817/. Accessed Nov 21, 2017)

Raghupathi W.and V. Raghupathi (2014) Big data analytics in healthcare: promise and potential Health Inf Sci Syst. Vol 2: 3.Published online 2014 Feb 7. doi: 10.1186/2047-2501-2-3

Raghupati W.(2010) Data Mining in Health Care. In: Kudyba S, editor. Healthcare Informatics: Improving Efficiency and Productivity. pp. 211-223

Sinha PS, G.; Bendale, P.; Mantri, M.; Dande, A. (2013) Electronic Health Record:Standards, Coding Systems, Frameworks, and Infrastructures: Wiley-IEEE Press

Sweeney, J. (2017). Healthcare Informatics. Online Journal of Nursing Informatics (OJNI), 21(1), Available at http://www. himss.org/ojni

WHO (2017) Universal Health Coverage Global Monitoring Report by the World Bank and World Health Organization December 13, 2017 Accessed 24th Dec 2017http://www.worldbank.org/en/topic/universalhealthcoverage/publication 